\title{
Crónica narrativa contemporánea: enfoques, deslindes y desafíos metodológicos ${ }^{1}$
}

\author{
Contemporary Narrative Chronicle: \\ Methodological Focuses, Demarcations and Challenges
}

\author{
Patricia Poblete Alday \\ Universidad Academia de Humanismo Cristiano, Santiago de Chile \\ ppoblete@academia.cl
}

RESUMEN: La crónica narrativa actual exhibe una serie de particularidades que no sólo vuelven interesante su estudio, sino que nos obliga, como investigadores, a replantear nuestras estrategias y herramientas analíticas. Sobre esa hipótesis, este texto aborda una serie de crónicas mexicanas contemporáneas, que tematizan las diferentes aristas de la violencia y el mal, para proponer una lectura crítica interdisciplinaria, que es la que creemos demanda este tipo de textos. Teniendo como eje comparativo los relatos de terror clásicos, focalizaremos aquí dos de los aspectos más Ilamativos de estas crónicas: a nivel temático, la reelaboración del motivo del "mal lugar"; y a nivel de la estructura, el valor de los silencios y huecos, tanto narrativos como referenciales.

\author{
Palabras Clave: \\ crónica narrativa; \\ periodismo y literatura; \\ México.
}

KEYWORDS:

Narrative Chronicle; Journalism and Literature;

Mexico.

\begin{abstract}
Current narrative chronicles have some particularities that make their study interesting, and also force us, as scholars, to rethink our analytical strategies and tools. On this hypothesis, in this text we study a series of contemporary Mexican chronicles, which thematize the different edges of violence and evil, to propose an interdisciplinary critical reading, which is what we believe this type of texts requires. Having as a comparative axis the classic horror stories, we will focus here on two of the most striking aspects of these chronicles: at the thematic level, the re-elaboration of the motive of the "bad
\end{abstract}

1 Este texto forma parte de los proyectos de investigación Fondecyt Regular № 1160027 y Fondecyt Regular № 1170993, de los cuales la autora es investigadora responsable y co-investigadora, respectivamente.

Literatura Mexicana |XXXI-1 | 2020 | 133-153 | DOI: 10.19130/iifl.litmex.31.1.2020.1143 
place"; and at the level of the structure, the value of silences and gaps, both narrative and referential.

recepcion: 07 agosto 2018

aceptación: 22 octubre 2018

El estudio de la crónica narrativa (o periodístico-literaria) actual nos plantea una importante problemática metodológica. ¿Cómo encaramos su análisis en la era de las Ilamadas "literaturas post-autónomas" (Ludmer 2010), cuando las fronteras genéricas han perdido fuerza y legitimidad, y por lo mismo, ni los abordajes narratológicos ni las perspectivas historicistas resultan ya pertinentes? La relevancia y la urgencia de este cuestionamiento se subrayan al considerar que el interés académico por la crónica se ha "congelado" en dos momentos/estrategias, cada uno de los cuales se corresponde con la "doble militancia" del "género": ${ }^{2}$ desde la literatura, dicho momento fue el Modernismo - lúcidamente analizado por Julio Ramos (1989) y Susana Rotker (2005) — mientras que desde las ciencias de la comunicación, el último punto históricamente relevante fue el new journalism de Tom Wolfe, en la década de 1970. Sin embargo, el corpus cronístico actual nos demanda para su comprensión que actualicemos nuestros aparatos conceptuales y herramientas analíticas, en sintonía no sólo con las cambiantes condiciones del contexto — que posibilitan el nacimiento y el desarrollo de este modo textual— sino también con elementos teóricos provenientes de otros campos del conocimiento, como las ciencias sociales, las artes y las humanidades.

Lo primero es definir qué es lo que hoy comprendemos por crónica periodístico-literaria, ya que en muchos países latinoamericanos tenemos la mala costumbre de llamar "crónica" a cualquier texto referencial con afanes estéticos: una columna personal, una crítica de cultura, un cuadro de costumbres, una greguería. Por ello, resulta esencial explicitar que comprendemos por crónica un texto periodístico, que se basa en los criterios

2 Excluimos, por razones de espacio, un tercer abordaje disciplinar de la crónica: desde la historiografía. Para un acercamiento a esta perspectiva resultan particularmente esclarecedores los estudios de Hayden White sobre las imbricaciones entre literatura e historia. 
de lo noticioso, ${ }^{3}$ pero remonta el mero afán informativo. Esto lo logra mediante cuatro estrategias complementarias y entrelazadas. Primero: inserta lo narrado en una corriente de hechos continua y significativa; a diferencia del periodismo informativo, esta crónica no se queda en la enunciación de las $5 \mathrm{~W}$ del lead (qué, quién, cuándo, dónde, por qué) sino que sitúa esos datos más allá de la coyuntura. Esto no sólo nos permite conectar explicativamente hechos noticiosos, sino también comprenderlos como manifestaciones o "síntomas" de un complejo entramado de factores, que son los que constituyen el "contexto". Es lo que hace Ryszard Kapuściński en El Sha o la desmesura del poder: situar hechos concretos —aquellos que desembocaron en la caída de Mohamad Reza Pahlavi, en 1979- dentro del devenir histórico-universal (en este caso, la lógica y dinámica de las revoluciones), de modo tal que aquellos pueden ser comprendidos más allá de su funcionalidad inmediata.

Como consecuencia de lo anterior, la crónica narrativa apela a constantes humanas universales, por lo que en ella se distinguen claramente las "historias" —o el encadenamiento de hechos- de las temáticas que le subyacen. Así, por ejemplo, en crónicas como El empampado Riquelme, de Francisco Mouat (2001), o "Perdido (missing)", de Alberto Fuguet (2007), el seguimiento de una pista noticiosa termina revelando el clásico motivo de la búsqueda del padre.

En tercer lugar, esta crónica enfoca desde un punto de vista propio y original. El Yo del cronista siempre está presente, como "una situación de la mirada" (Caparrós: 502) antes que como pronombre. En consecuencia, y en oposición a lo que sucede en el periodismo informativo, en la crónica narrativa es dable distinguir al autor (persona) del narrador (entidad textual). Es lo que sucede, por ejemplo, cuando Elena Poniatowska asumía el rol de "niña fresa" para interpelar a sus entrevistados, logrando piezas notables como la entrevista a Cantinflas incluida en el segundo tomo de Todo México (1995).

Por último, esta crónica desarrolla el aspecto estético de la materialidad textual, utilizando recursos narrativos tradicionalmente asociados a

3 Carl Warren (1975) identificó los elementos que componían lo "noticioso": actualidad, proximidad, prominencia, curiosidad, conflicto, suspense, emoción y consecuencias. 
la ficción y vetados de la economía de la nota periodística informativa. Es importante notar que este aspecto estético es consecuencia del punto anterior —la mirada - y no es constitutivo, por sí solo, de lo "narrativo" o "literario" de este tipo de textos. Vale decir: una crónica no es "literaria" porque su autor utilice metáforas, juegue con los tiempos del relato o exhiba un dominio del lenguaje que va más allá de lo referencial; su espesor estético deriva de cierto enfoque hacia la realidad que se busca encuadrar, no hacia el texto, y ese enfoque suele estar regido por un criterio ético. La estructura de mosaico de La noche de Tlatelolco (1971), por ejemplo, revela una posición política ante lo narrado: todos los testimonios tienen la misma importancia (aquí las palabras de Octavio Paz valen lo mismo que las de una actriz desconocida, o de un estudiante secundario), y la colectividad aparece no como una masa indiferenciada, sino como suma de individualidades. Las voces e historias fragmentadas replican la fuerza de las manifestaciones callejeras no sólo en el nivel del contenido, sino también desde el porqué de su ensamblaje. De modo similar, al reproducir la matriz dramática del guion del noticiario televisivo, Daniela Rea apunta, en la crónica "Caminando en la tormenta" (2015: 63-101), a desmantelar la lógica massmediática ${ }^{4}$ que encasilla y estereotipa tanto personajes como situaciones.

\section{La violencia y el mal en la crónica mexicana}

La investigación en la que se enmarca este texto procura poner en práctica una perspectiva interdisciplinaria para el estudio de la crónica, y se centra particularmente en aquella que aborda la temática de la violencia en sus distintas manifestaciones (como la crisis migratoria, el narcotráfico, las

4 Si bien el soporte y el lenguaje digital constituyen una dimensión relevante dentro del ejercicio periodístico y literario en la actualidad, nuestro corpus analítico se sirve de principalmente crónicas publicadas en formato libro (antologías colectivas o individuales); esto sobre la premisa (y la promesa) de perdurabilidad y valor estético que aquél posee (Chartier 1993, 2009), y que le otorga un estatus diferente al del periódico. Como bien señala Darío Oses (s/f): "es en estas compilaciones, especialmente en las temáticas, donde la crónica revela toda la potencia literaria que no siempre puede advertirse en la lectura fragmentaria que se hace de ellas en los periódicos". 
pandillas, la corrupción, etc.). ${ }^{5}$ Por lo mismo, en buena medida, nuestro corpus analítico se compone de textos escritos por periodistas mexicanos, como Marcela Turati, Alejandro Almazán, Daniel de la Fuente, Galia García, Diego Enrique Osorno, Humberto Padgett, Javier Valdez, Daniela Rea, Fernanda Melchor, Edgar Piñón Balderrama y Héctor de Mauleón.

Lo primero que identificamos como una corriente temática común entre estos textos es que la violencia aparece como una manifestación concreta de algo más abstracto y atroz: el mal, concebido como una fuerza omnipresente que se enseñorea de todos los aspectos de lo cotidiano. Las distintas formas que adopta la violencia vienen a ser concreciones esporádicas y proteicas de un mal banal, como lo llamó Hannah Arendt (1963), o liberado, según la reconceptualización de Baudrillard (1993). Quizás uno de los ejemplos más contundentes de ello sea la naturalización de esa violencia ya desde del imaginario infantil, como leemos en las crónicas "Armas de juguete" y "Francisco", de Javier Valdez (2016), o en "Juegan a ser sicarios" de Daniela Rea. Citamos de esta última:

Brenda tiene 12 años y le gusta cantar corridos al mando de su camioneta Pontiac último modelo. Brenda baja la ventanilla, y sin frenar, saca su pequeña mano que sostiene una pistola $.9 \mathrm{~mm}, \mathrm{y}$ dispara al otro lado de la calle.

Brenda acaricia su $.9 \mathrm{~mm}$. Le ha dejado recuerdos en su cuerpo: un moretón en el labio superior, y varias heridas en los brazos. Y es que, [sic] a su corta edad, dice, las balas de goma le hieren, pero son indispensables para jugar (2012: 177).

Cuando el mal ha dejado de ser la excepción para convertirse en la norma, el psicópata es reemplazado por el sicario; el terrorista por el narco; el sádico por el pandillero. En este sentido, la psicoanalista Élisabeth Roudinesco señala el afán de las sociedades posmodernas y globalizadas por "borrar el mal, el conflicto, el destino, la desmesura" (2009: 182-183),

5 Comprendemos el ejercicio de la violencia en la época contemporánea no ya desde la diada Estado/Delincuencia, sino dentro de lo que Deleuze y Guattari (1994) Ilaman "máquinas de guerra": organizaciones difusas, móviles y proteicas, que administran el miedo y la muerte sobre un criterio de eficiencia y rentabilidad. Esta concepción de la violencia contemporánea está en la base de propuestas particularmente pertinentes al análisis de la realidad mexicana actual, como las de necropolítica (Mbembe 2006) y capitalismo gore (Valencia 2010). 
y ese afán es rastreable en el tratamiento mediático de los hechos delictuales. Pero el tratamiento de los tópicos que el mal acarrea —robo, corrupción, muerte, violación, etc.- presenta en estas crónicas que analizamos diferencias notables en relación a las páginas rojas, que era el espacio donde tradicionalmente se consignaban los hechos delictuales. El sensacionalismo sería la matriz que genera esas diferencias, en tanto se focaliza en la espectacularidad del detalle morboso, impidiéndonos pasar a un grado mayor de abstracción reflexiva sobre aquellos temas que laten tras el charco de sangre. Como indica el argentino Damián Fernández Pedemonte,

los medios siguen una estrategia de tenaza: por un lado, [sic] seleccionan los acontecimientos violentos fuertes porque su negatividad y novedad se ajusta a los valores de la noticia. Pero, por otro, reducen la extrañeza del fenómeno, de tal manera que se muestre siempre como algo externo al sistema, anómalo y fácil de condenar (2001:124).

En la crónica narrativa, por el contrario, el hecho criminal se inserta dentro de un proceso mayor que, a su vez, responde a dinámicas sociales que van más allá de la lógica "buenos contra malos". El mal opera como un horizonte de inteligibilidad complejo y universal, que cobija todos los ribetes de la violencia: el legal, el psicológico, el sociocultural, el biológico, permitiéndonos un grado de implicación que resulta imposible dentro de la economía informativa de la nota roja. Los cronistas actuales son conscientes del desafío que ello impone para su trabajo; ejemplo de ello es el testimonio de Ismael Bojórquez, uno de los fundadores del semanario Ríodoce. Ante la pregunta sobre la cobertura que hacen los medios de comunicación mexicanos del fenómeno del narco y sus consecuencias, aquél responde: "Todos hablan de las balaceras, publican fotos de los decapitados o, como Milenio, contabilizan a los muertos. No hay más. Proceso es el mejor que lo hace, aunque abusa del tema. Televisa llena sus noticiarios de violencia pura, pero no la entiende. A El Universal le ocurre lo mismo. Reforma trata el tema muy tímidamente. Nadie hace un tratamiento a fondo" (en Almazán 2010: s/p).

A diferencia del dualismo simplista que abunda en la nota policial, la crónica narrativa nos devela la fragilidad de las fronteras que separan 
el bien del mal, para desde allí enfrentarnos a las posibilidades que nos brinda el libre albedrío. Porque sabemos que las circunstancias —el lugar incorrecto, la hora inoportuna- pueden hacer de nosotros víctimas, pero ¿somos conscientes de que también pueden volvernos victimarios? ¿Podemos dar fe de que siempre obraremos según los valores que se nos inculcaron? Que no hayamos nacido asesinos, ¿significa que nunca llegaremos a serlo? Todas estas interrogantes —expuestas en la famosa investigación del psicólogo Phillip Zimbardo en torno al experimento de la cárcel en la universidad de Standford realizado en 1973 (2008) - se reabren en crónicas como las que estudiamos. Por citar sólo una: la de Marcela Turati sobre Santiago Meza López, "El Pozolero" (2015), donde, contraria a la imagen colectiva de un brujo que revuelve con indolencia un guiso humano, Meza López se nos revela también en su faceta de hombre humilde: un desempleado al borde de la desesperación por no poder alimentar a su familia; un asalariado que se esfuerza por cumplir con eficiencia el trabajo que le han encomendado.

El mal, en otras palabras, opera en estos textos como un dispositivo que está en la base de la representación de la realidad, y rige cada etapa de producción textual desde la selección del material (las imágenes, las declaraciones de los protagonistas y los testigos, los principales sucesos, etc.) hasta su arquitectura. Desde el Análisis Crítico del Discurso, comprendemos que la identificación de los textos en base a ciertos hilos discursivos o temas resulta esencial para comprender la crónica más allá de su función informativa-referencial. ${ }^{6}$

Sobre esa base contextual nos podemos volcar sobre la especificidad narrativa de la crónica. Esto es: cómo se cuenta ese mal que identificamos como eje rector de estos textos. La primera respuesta es que lo hace echando mano de recursos literarios, y aunque no es incorrecto referirlo así, sí es posible —y deseable— algo más de precisión. Lo que identificamos en esta investigación es que este tipo de crónica da cuenta de las diversas formas del mal utilizando estrategias propias del relato de horror clásico. Ambos textos exploran los límites de la experiencia humana, ha-

6 Para una profundización sobre este punto, véase la compilación de Ruth Wodak y Michael Meyer (2003), en especial el texto de Siegfried Jäger. 
ciendo hincapié en el espanto de ver cómo la razón cede al influjo de unas fuerzas atávicas y bestiales, que emergen sin pudor ni control.

Elocuente en este sentido resulta que la compilación de crónicas Aquí no es Miami (2018), de Fernanda Melchor, emparente el registro marcadamente referencial —siempre apuntando al enseñoramiento de los cárteles que trafican droga en Veracruz- con la lógica narrativa fantástica. Esto, que se asoma apenas en textos como "Luces en el cielo", donde las avionetas de los narcos se confunden con ovnis, se desarrolla con eficiente soltura en "La casa del estero", relato que reedita el tópico del mal lugar (que profundizaremos más adelante) echando mano del clásico recurso de la pandilla adolescente que irrumpe en los límites de lo prohibido (la casa embrujada). Lo demoníaco que toma posesión de lo humano se vuelve aquí correlato de ese mal "otro", pero tangible, que corrompe el cuerpo social. Así, se establece una continuidad semántica entre los "[f]antasmas en harapos que duermen la mona en el suelo de los callejones; espantos de carne y hueso que asoman sus rostros tiznados por las celosías rotas de los balcones" (2018: 43-44), y aquellos otros seres, infrahumanos, que poblaban los relatos de terror ficcional.

En este horizonte comparativo, señalaremos aquí dos aspectos que la crónica recoge de la ficción gótica, adaptándolas a su fisonomía y su finalidad.

\section{Arquetipos narrativos}

El primero, y más evidente, es la selección y composición de los motivos y figuras que nutren el universo narrativo. En otros lugares hemos examinado cómo en estas crónicas se reelaboran imágenes y temas propios del género fantástico, como el monstruo y el fantasma (2018); aquí nos centraremos en el imaginario del infierno real y secularizado. México aparece en estos textos como un espacio ominoso, lleno de peligros y emboscadas tanto para los migrantes que lo cruzan de manera ilegal, camino a Estados Unidos, como para el ciudadano de a pie, que vive expuesto a índices de violencia crecientes. Sólo unos cuantos ejemplos: Humberto Padgett llama a Tamaulipas "un agujero negro" (2012: 153); Marcela Turati designa a Ciudad Juárez como "una moderna necrópolis" (2012: 234); Alejandro 
Almazán considera que el estado de Chihuahua es una "máquina de la muerte", de la que "no para de escurrir la sangre" (2011), y Diego Enrique Osorno señala que Monterrey es un "lugar malhadado" (2014: 127) que "tiene algo bien podrido dentro" (128). Un parque en el cual juegan los niños es también escenario de masacres a sangre fría, que parecen ejecutadas por fantasmas (Fuente 2012). El surgimiento y expansión de los cárteles tiene el efecto de "cubrir el país entero con una sombra" (Mauleón 2015: 182) y convertir a ciudades otrora bulliciosas en "pueblos fantasmas que habitaban sombras pertrechadas en sus casas" (292). El tópico clásico del "mal lugar" se expande por la geografía mexicana, liberado, volviendo extraño lo propio y familiar, ${ }^{7}$ al punto de que las palabras de Stephen King sobre la ficción de terror se aplican perfectamente a la crónica en este punto: "Cuando llegamos a casa y echamos la llave a la puerta, nos gusta pensar que estamos dejando fuera los problemas. La buena historia de horror acerca del Mal Lugar nos susurra que no estamos dejando fuera el mundo, sino que nos estamos encerrando... con ellos" (2006: 389).

En la serie de crónicas sobre el programa "Frontera Sur", publicado por el sitio de internet Animal Político (2015), el sur de México aparece como un territorio para la caza de migrantes: lo que desde el discurso oficial se presenta como una estrategia humanitaria, acaba revelándose como un nuevo peligro para quienes cruzan el territorio con rumbo a Estados Unidos. En esta misma línea, en el norte, el desierto retoma sus ancestrales connotaciones malignas para revelarse como "el reino mismo de la Nada o la emergencia sensible del abismo sin fondo y sin fundamento" (Trías 2009: 35), mientras que los villorrios de la frontera se vuelven pueblos fantasmas; ciudades de deportados que apenas se detienen allí antes de regresar a sus ciudades de origen. El inicio de la crónica "Muerte en el desierto", de Marcela Turati, es elocuente al respecto, y bien vale la extensión de la cita:

Secos como ramas. Así quedaron, esparcidos en los pedazos de desierto. Desde el tercer día de su caminata por el desierto de Arizona, uno por uno, fueron vencidos por el infierno. Uno, desesperado, abrazó un cactus y flageló su cuer-

7 Recuérdese que, según Freud, la definición de lo ominoso es "aquella suerte de espantoso que afecta las cosas conocidas y familiares desde tiempo atrás" (10). 
po con las espinas; Edgar Adrián, de 23 años, veracruzano de Coatepec, se desvaneció bajo la sombra de un matorral, refresco inútil. Frente a él, su tío José Isidro lo vio que apretó los párpados, Iloró dos lágrimas y expiró. Arnulfo, el padrino de Edgar, también de Coatepec, tierra caliente y húmeda, de cafetales, tampoco aguantó. Alcanzó a esconder su cuerpo en el hoyo de un tronco. Los 47 grados derritieron su desesperación. Vino un grito y una convulsión.

Un día después, el 23 de mayo de 2001, agentes de la Patrulla Fronteriza descubrieron huellas en el suelo del Refugio Silvestre de Cabeza Prieta, condado de Yuma, que los condujeron a hombres semidesnudos con los ojos secos. A cuerpos quemados, regados por el desierto, abandonados por sus parientes que seguían arrastrándose en busca de agua. A muertos y vivos sentados bajo la misma sombra. A un hombre con manos ardidas por cavar un hoyo en las dunas para enterrarse y esconderse del sol.

Hallaron a 14 mexicanos muertos y 12 vivos que, [sic] durante 5 días, tres sin agua y sin comida, caminaron por la llamada "Ruta del Diablo" siguiendo a Jesús López Ramos, un "coyote" perdido que los dejó abandonados. Se toparon, también, con una de las peores tragedias migratorias de las que en México se tiene memoria (2006: 521-522).

Así presentado, el territorio se hace espacio propicio para el desarrollo de una monstruosidad que es, ante todo, ética, y que encarna de manera privilegiada en "La Bestia" y "El Diablo", los ferrocarriles de carga que recorren el sur y el oeste mexicano, respectivamente. Esta monstruosidad, sin embargo, no siempre es tan explícita ni directa, como se observa, con particular elegancia, en el texto "De cartón piedra", de Javier Valdez, donde se relata una masacre en un centro comercial. La perspectiva del relato focaliza desde un maniquí femenino en uno de los escaparates, que observa la tragedia inmóvil y estupefacta; "[t]an como siempre y tan como si nada" (2016: 101). Su rigidez física —en la que late el motivo fantástico del autómata- exterioriza tanto la impotencia como el adormecimiento crítico de la población: "[Y ella] aguantó el estruendo del accionar de las armas y luego los gritos y luego el ulular de las patrullas, y siguió con la mirada extraviada y la sonrisa puesta en el rostro, afable y ofrecida" (101).

El mal, sin embargo, no es aquí una amenaza externa y desconocida que debamos padecer: el territorio no hace sino manifestar las pulsiones inconscientes y atávicas que nos Ilevan a ser despiadados. La violencia "ambiental" aquí es sólo el primer estadio, el contexto propicio para que germine la crueldad y cristalice en violaciones grupales, descuartizamien- 
tos, empalamientos, entambados, y en un sinfín de torturas. Esto no significa que la perpetración de actos malévolos no sea resultado de una cadena de elecciones conscientes; como indica Wolfgang Sofsky: "El aspecto exterior de la violencia conoce multitud de formas. Pero es siempre la cultura la que las crea. Es la cultura, y no la naturaleza, la que ha hecho al hombre ser lo que ha sido y continúa siendo" (222). Y abunda: "A pesar de todos los esfuerzos morales, a pesar de todas las tentativas de dominar la brutalidad, el mal continúa existiendo; es imperecedero. Los estratos más primitivos del alma son lo verdaderamente inmortal" (225).

Porque no hablamos de simples asesinatos: antes de la muerte hay humillación, hay sufrimiento ralentizado, hay torturas que se administran con efectividad, muchas veces con la asistencia de profesionales que ayudan a "revivir" a la víctima para someterla a nuevas sesiones de dolor. Hablamos del sadismo de quien se complace en ejercer su dominio sobre los demás; hablamos, también, de la indiferencia de quien es incapaz de sentir compasión o empatía. En el primer caso podemos citar el caso del grupo de sicarios que, no contentos con lanzar a su víctima a las fauces de un enorme cocodrilo, se solazan echándole cocaína en las heridas (Valdez 2017: 163-164). En el segundo, la frialdad con la que una pistolera — Vanessa- asegura que no la asaltan los remordimientos "ni la despiertan durante la madrugada las súplicas o llantos o las miradas de los que tuvo que mirar a los ojos" antes de ejecutar (183); o la rapidez con la que otra pistolera - Yaretzi- responde cuando el cronista le pregunta cuánto cobraría por matarle a él: "Vales lo mismo que toda la demás gente, nada [...] el muerto vale las balas que le metas y aquí nos las venden a diez pesos" (Almazán 2011: s/p).

Como hemos señalado, lo que nos interesa enfocar aquí es el relato de esa maldad, que procura racionalizarla para hacerla comprensible. Por supuesto, ello no equivale a justificarla. Así, la "personificación" de objetos inanimados como los trenes, expresada con claridad en sus motes de "La Bestia" y "El Diablo", viene a ser tanto una proyección de esas pulsiones agresivas como un ejemplo de este proceso narrativo por el cual tratamos de entender algo tan abstracto e inasible como el mal. 


\section{Lo "inenarrable"}

Esta monstruosidad se replica en un sinfín de acciones de crueldad creciente y terrible, que son, como en los relatos clásicos de terror, "inenarrables". Así se explica buena parte de los silencios que caracterizan esta crónica, y que constituyen el segundo aspecto narrativo en el que nos detendremos. No se trata de las "lagunas de indeterminación" señaladas desde la teoría de la recepción, ya que el sentido de lo elidido queda aquí bastante claro. Todos comprendemos qué significan los papeles que se deslizan bajo una puerta, las líneas telefónicas que se quedan mudas, los jefes de policía que no llegan a la estación un lunes por la mañana. La omisión narrativa se justifica al menos en dos sentidos: primero, en tanto forma de evitar el morbo y violentar en exceso la sensibilidad de los lectores; segundo, en tanto el contexto permite prescindir de detalles narrativos sin sacrificar la inteligibilidad del escrito. Los textos de Malayerba, de Javier Valdez, constituyen un claro ejemplo de esto: el narrador apenas esboza situaciones y personajes, que hacen eco con facilidad en un imaginario colonizado por el miedo, el peligro y la muerte. El diálogo telefónico cargado de sobreentendidos que recibió Edgar Piñón Balderrama siendo editor de un periódico, y que reproduce en su crónica "Mi vida con el narco", es elocuente en ese sentido:

- Licenciado, un gusto saludarle, licenciado. Me recomendaron que hablara con usted para platicar de... bueno, es que, mire, pues nosotros no queremos problemas con ustedes, ¿sí me entiende, patrón?, es que queremos que nos echen la mano, porque son chingaderas lo que están haciendo con nosotros y pues no queremos actuar a la mala. A nosotros no nos gusta meternos con los que nomás hacen su trabajo, sabemos que nomás hacen su trabajo, pero también nos están chingando, les dicen que nos están chingando y ya no sabemos cómo hacerle... ¿sí me entiende, licenciado?

Desde luego que lo entendía (2016).

El horror se ha vuelto tan cotidiano, que el cronista puede permitirse reeditar sobre él un género antiguo: el cuadro de costumbres. Las señas de identidad no hacen falta, ya que lo narrado aborda una realidad que se vive en cualquier parte: el adolescente que deja la escuela por la promesa de un futuro esplendor bajo el ala del narco; la madre soltera que busca 
un padre para sus hijos en el amante generoso y violento; el hijo que busca venganza contra quien masacró a su familia; la prostituta adolescente, dura y descreída; el policía corrupto, primero por obligación y luego por comodidad... Aquí la recurrencia de las situaciones, y de los tipos humanos, es lo que marca el inicio del horror: lo que se muestra no es una excepción, sino una realidad cada vez más común.

Cualquier lector o espectador de historias de espanto sabe que el silencio es un recurso eficaz en la generación de tensión. La promesa instalada por el ralentí de las acciones ("algo va a pasar") se enseñorea no sólo de las coordenadas espaciales, sino también de las temporales. En el pasado: algo terrible ha sucedido aquí, y el lugar guarda memoria de esos hechos; no es necesario que nada ocurra para que lo percibamos. En el presente: algo malo se está gestando en este preciso momento; prueba de ello es que pareciera que todo está en calma, que nada sucede. En el futuro: algo espantoso se desencadenará, en cualquier minuto, y la espera es parte de ese espanto. Tal como lo leemos en una crónica de Galia García: “La presidencia municipal de Pradexis está al lado de la comandancia de policía, frente a la plaza, que no es distinta de la mayoría de las plazas de pueblo de todo el país. La de Pradexis tiene bancas verdes y un quiosco rosa. El lugar entero es de un silencio aterrador" (71-72).

A nivel lingüístico, esto también se manifiesta en la supresión - textual, pero también cultural- de ciertos vocablos fuertemente connotados. Al hacer hincapié en ello, los cronistas acentúan la carga simbólica de lo elidido, potenciando su impacto. Es lo que hace Marcela Turati apenas inicia su texto sobre "El Pozolero":

¿Y él qué explicaciones da acerca de eso?

Me creerá que de eso no me ha dicho. Cuando le digo, sólo me responde:

"Tú mejor que nadie sabes cómo soy yo".

[...]

A Irma se le traban las palabras cuando quiere referirse al empleo de Santiago Meza López, su marido. Habla de "ese trabajo", da rodeos ("cómo le puedo decir"), hasta que finalmente termina por llamarlo "eso" (2015: 93).

Diego Enrique Osorno profundiza en esta operación, en La guerra de los Zetas: 
No sabemos cómo nombrar lo que sucede en esta región del país, donde la evasión mental de la realidad crece, donde un eufemismo ayuda a no perder la cordura.

Conozco a un grupo de niños de entre ocho y diez años que, por adiestramiento de sus papás, tienen prohibido mencionar palabras como narcos, zetas, soldados... En lugar de cada una de estas palabras tan presentes en Monterrey, deben decir "bolitas de nieve".

[...]

Uno de esos niños me dijo que fueron bolitas de nieve las que sembraron el terror en Cadereyta un domingo al amanecer (2014: 137).

Asimismo, el silencio que se subraya en el texto marca la inconveniencia de invocar aquello que se nombra, tal y como en los ritos paganos. Así se entiende la costumbre de no nombrar a los Zetas, y reemplazar su nombre con eufemismos: "los de la última letra" (Melchor 2018: 148), "la gente" (Osorno 2014: 54), "la Compañía" (169). O en lo innecesario de abundar en explicaciones cuando ya todo el mundo sabe a qué nos referimos, como sucede en la crónica "Porque nos encontramos no sucumbió la eternidad", de Daniela Rea, donde se señala que "hasta entonces [agosto de 2010, cuando se dio a conocer la existencia de la fosa con 72 cadáveres de inmigrantes], San Fernando no era aún San Fernando" (2015: 237).

En términos estructurales, el silencio semántico juega un papel relevante, indicando la imposibilidad de completar una historia lógicamente. Antecedentes que no existen y causalidades imposibles: aquello que en la ficción sustenta el absurdo, en el plano de lo referencial se vuelve horroroso, precisamente porque es real. Lo kafkiano se vuelve real. Así, los casos de ciudadanos que son detenidos y encarcelados de manera antojadiza, sin más evidencia que la suposición de culpabilidad por parte de los agentes de la policía, generan relatos que no pueden narrarse sino in medias res, asumiendo desde el inicio que lo que se va a narrar/leer es sólo la parte visible del iceberg, y que el resto —el "resto" que contendría los fundamentos y las explicaciones racionales- permanecerá oculto, o que simplemente no existe. Casos como estos nutren crónicas como "Las jaulas de la justicia", de Héctor de Mauleón (2015) o "Bajo el ondear de la bandera", de Daniela Rea (2015). En ambas, personas comunes y corrientes se ven bajo el foco de los medios porque alguien, en algún momento, 
por razones desconocidas, decidió que serían ellos - y no otras personas, igualmente elegibles - quienes aparecerían públicamente como chivos expiatorios de un sistema corrupto.

Habría que agregar, por último, una tercera justificación para la omisión narrativa: la supervivencia. Muchos cronistas han hecho notar la imposibilidad de publicar toda la información relacionada con el narco sin arriesgar la propia vida; los índices de asesinatos de periodistas en México durante los últimos años son prueba irrefutable de ello. Ante esta situación, la autocensura se presenta como un ejercicio de autocuidado y no como una estrategia de control político, según dejó escrito Javier Valdez antes de ser ultimado, precisamente, en represalia por su labor periodística (2017: 338-342).

\section{Conclusiones}

Es importante notar que el uso de estos recursos narrativos presupone un lector activo y al día con la actualidad noticiosa: pese a que la crónica narrativa nace desde la lógica periodística, su finalidad no es informar. Por lo mismo, también presuponen esos textos periodísticos que sí son informativos, y que ayudan a configurar la concepción de la realidad sobre la cual leemos y asimilamos la crónica. Ambos elementos — la recepción del texto, y sus antecedentes - nos ayudan a ajustar el aparato analítico al objeto de estudio, evitando la simple aplicación de modelos externos a un texto cerrado. Esto último es lo que sucede, por ejemplo, cuando aplicamos esquemas narratológicos o lingüísticos al estudio de las crónicas: podemos identificar motivos, trayectos actanciales, regularidades o desvíos léxicos, pero en la práctica anulamos la complejidad de este tipo de textos, que viene dada precisamente de su permeabilidad a las circunstancias contextuales, y que son las que nos demandan herramientas analíticas diversas: más allá del periodismo, más allá de la literatura.

Es importante notar que la adopción de estrategias analíticas provenientes de distintas disciplinas nos permite analizar las transformaciones históricas de las disciplinas involucradas en su producción; en el caso que nos ocupa, abre la posibilidad de resituar la labor del periodismo, más allá de lo informativo, dentro de una reflexión de corte universal y humanística; 
a la vez que nos obliga a repensar la condición de lo literario, en general, y las fronteras y definiciones del género fantástico, en particular. Además, nos permite comprender dimensiones no-textuales de la crónica que son relevantes para su correcta comprensión, como su valor en tanto discurso dentro del campo cultural; los usos que los lectores hacen de este modo textual; o las estrategias sociales de construcción de una verdad consensuada. Si bien todos estos son aspectos que sobrepasan, con mucho, los límites de este artículo, no quisiéramos concluir sin esbozar al menos dos consideraciones respecto a la recepción de este tipo de crónica.

La primera tiene que ver con el lector; más específicamente, con las motivaciones que lo acerca a esta forma narrativa del horror. Si bien son conocidas las teorías que indican que el entusiasta de este género satisface con él sus deseos psicosexuales profundos y reprimidos (Jackson 1988; Carroll 2005), ¿qué sucede cuando lo horroroso desborda lo ficcional y se instala dentro de lo real? ¿Qué pasa con el placer vicario de ver proyectados nuestros impulsos más agresivos cuando el escenario de esa proyección no es sino nuestro entorno cotidiano? ¿Disfrutamos de la misma forma el horror cuando su amenaza se vuelve real?

Sofsky (105-108) indica que el espectáculo de la violencia real, al igual que la ficcional, nos fascina y nos horroriza a la vez, lo que ya da cuenta de ese cruce de pulsiones que nos constituye en tanto seres humanos. Sin embargo, dentro de esa ambivalencia es posible realizar una sutil distinción: lo que nos atrae son los actos crueles — la soberanía y rotundidad con la que se expresan; su oscura magnificencia- no el sufrimiento de las víctimas. En su lectura de un subtipo de horror, el de tortura (que, a diferencia del horror fantástico, nunca es supernatural, mágico o religioso, sino real), Jeremy Morris (2012) hace notar que su público debe tener un rango de empatía alto y amplio, que le permita tanto compadecer a la víctima como comprender el placer que experimenta el victimario. Esto no significa que el lector/espectador posea tendencias masoquistas o sádicas; muy por el contrario, el choque de sentimientos que surge de su empatía doble y contradictoria le genera un fuerte conflicto ético que evidenciaría, según Morris, su talante moral.

Una primera proyección de este estudio apunta en esa dirección: profundizar las similitudes y diferencias entre el público del horror ficticio y 
el público de este otro horror real del que hablan las crónicas. ¿Es el mismo impulso el que nos lleva a exponernos a lo terrorífico ficcional y a lo terrorífico real? ¿La empatía se activa de la misma forma ante personajes que ante personas de carne y hueso? ¿El horror se experimenta con mayor intensidad en alguna de las dos variantes? ¿La inmediatez del peligro modifica la experiencia lectora? ¿En qué grados y en qué sentidos? Todas estas son cuestiones de sumo interés que convocan, nuevamente, una mirada interdisciplinaria donde caben no sólo la literatura y el periodismo, sino también la psicología, la sociología y la neurociencia.

La segunda consideración atañe al potencial de estas crónicas más allá de su valor informativo y referencial, e implica inscribirlas dentro de lo que José Ovejero llama "literatura de la crueldad". Aquí el texto mismo es una forma de violencia que interpela al lector para forzarle a ver aquellas partes oscuras de la realidad y empujarle hacia la acción social. El autor asume el rol de verdugo mientras su lector accede a ser su "víctima"; sin embargo, la crueldad que está en la base de esta relación ya no es de carácter voluptuoso sino ético, en tanto apunta a provocar y remecer. "El puñetazo se dirige a las tripas pero, si es suficientemente violento, repercute en el cerebro" (Ovejero 2012: 101). El "daño" que se le hace al público no es el fin, sino apenas el medio para lograr un cambio real. Con ello, indica Ovejero, esta literatura aspira a "desgarrar el velo de la ilusión" (197), en contraposición a la lógica de la violencia espectacular, massmediática, que transforma los impulsos de agresividad del público en sublimación socialmente inoperante, agotándose en el entretenimiento. Así, las películas que se realizan sobre esta lógica, "[m]ás que atacar la moral establecida, son una válvula de escape a la represión que toda moral impone; pero no cuestionan ésta, sencillamente invitan a ignorarla durante unas horas en la oscuridad del cine o en la clandestinidad de la propia vivienda" (39).

Desde aquí, una segunda proyección de este trabajo podría orientarse a descubrir las consecuencias de esta crónica comprendida como provocación, esto es: la crónica como acto perlocutivo. En México, la organización Periodistas de a Pie constituye un fabuloso ejemplo de las consecuencias concretas que puede tener el desarrollo de un modo textual que va más allá de lo informativo, y que nos puede mostrar nuevos modos de 
entender el oficio periodístico, de representar la realidad, y de mirarnos a nosotros mismos.

\section{Bibliografía}

Almazán, Alejandro. "Periodismo en la boca del lobo", en Gatopardo, 111 (mayo de 2010). Artículo en línea disponible en: <https:/gatopardo.com/reportajes/ periodismo-en-la-cueva-del-lobo-javier-valdez-riodoce-sinaloa/> [consultado el 04 de febrero de 2018].

Almazán, Alejandro. "Chicas Kaláshnikov", en Gatopardo, 118 (febrero de 2011). Artículo en línea disponible en: <https:/gatopardo.com/revista/no-111-mayo-2010/mujeres-sicario/> 2011 [consultado el 12 de mayo de 2018].

ARENDT, HanNaH. Eichmann en Jerusalén [1963]. Carlos Ribalta (trad.). Barcelona: Lumen, 2003.

BAUDRILLARD, JEAN. La ilusión de fin. La huelga de los acontecimientos. Thomas Kauf (trad.). Barcelona: Anagrama, 1993.

CAPARrós, Martín. La crónica. Madrid: Círculo de Tiza, 2015.

CARroll, NoëL. Filosofía del terror o paradojas del corazón. Madrid: Machado Libros, 2005.

ChARTIER, Roger. Libros, lecturas y lectores en la edad moderna. Madrid: Alianza, 1993.

ChArTIER, Roger. El libro y sus poderes (siglos XV-XVIII). Medellín: Universidad de Antioquía, 2009.

Deleuze, Gilles y Félix Guattari. Mil mesetas. Valencia: Pretextos, 1994.

Fernández Pedemonte, Damián. La violencia del relato. Discurso periodístico y casos policiales. Buenos Aires: La Crujía, 2011.

Freud, Sigmund. Lo siniestro [1919]. Trad. Ludovico Rosenthal. México: Letracierta, 1978.

Fuente, Daniel de la. "Partes de guerra", en Generación ¡Bang! Nuevos cronistas del narco mexicano. Juan Pablo Meneses (comp.). México: Temas de Hoy, 2012. 37-55.

Fuguet, Alberto. "Perdido (missing)", en Apuntes autistas. Santiago de Chile: Aguilar, 2007. 357-374.

García, Galia. "La mujer más valiente de México tiene miedo", en Generación ¡Bang! Nuevos cronistas del narco mexicano. Juan Pablo Meneses (comp.). México: Temas de Hoy, 2012. 61-77.

JACKSON, Rosemary. Fantasy, the literature of subversion. Nueva York: Routledge, 1988.

KAPUŚCIŃSkI, RYSZARD. El Sha o la desmesura del poder. Agata Orzeszek (trad.). Barcelona: Anagrama, 2006.

KING, StePhen. Danza macabra [1981]. Óscar Palmer (trad.). Madrid: Valdemar, 2006.

Ludmer, Josefina. Aquí, América Latina. Una especulación. Buenos Aires: Eterna Cadencia, 2010. 
Mauleón, Héctor de. Roja oscuridad. Crónica de días aciagos. México: Planeta, 2015.

Mbembe, Achille. Necropolítica [2006]. Elisabeth Falomir Archambault (trad.). Santa Cruz de Tenerife: Melusina, 2011.

Melchor, Fernanda. Aquí no es Miami. México: Random House, 2018.

MORRIS, JeREMY. "The Justification of Torture-Horror. Retribution and sadism in Saw, Hostel, and The Devil's Rejects", en The philosophy of horror. Thomas Fahy (ed.). Kentucky: The University Press of Kentucky, 2012. 42-56.

Mouat, Francisco. El empampado Riquelme [2001]. Santiago de Chile: Lolita Editores, 2012.

OSES, DARío. "Crónica de cronistas", s/f. Biografía en línea disponible en: <http:// www.nuestro.cl/ opinion/columnas/cronistas1.htm> [consultado el 4 de marzo de 2011].

Osorno, Diego Enrique. La guerra de los Zetas. Viaje por la frontera de la necropolítica [2012]. México: Debolsillo, 2014.

Ovejero, José. La ética de la crueldad. Barcelona: Anagrama, 2012.

Padgett, Humberto. "Los desaparecidos de Tamaulipas", en Generación ¡Bang! Nuevos cronistas del narco mexicano. Juan Pablo Meneses (comp.). México: Temas de Hoy, 2012. 153-172.

Pinón Balderrama, Edgar David. "Mi vida con el narco", en vvaA. La ley del cuerno [ $1^{\text {a }}$ ed. impresa 2011]. Versión digital para Kindle. Caracas: Puntocero, 2016 [crónica publicada originalmente en la revista Nexos y el diario El Heraldo de Chihuahua (diciembre de 2009)].

Poblete Alday, Patricia. "Monstruos posmodernos. Figuras de la inmigración en el México contemporáneo", en Chasqui. Revista de Literatura Latinoamericana. Arizona State University, XLVII-1 (mayo de 2018): 249-258.

Poniatowska, Elena. La noche de Tlatelolco. Testimonios de historia oral. México: Era, 1971.

Poniatowska, Elena. "Cantinflas" [1953], en Todo México, vol. II. México: Diana, 1995. 175-181.

"Programa Frontera Sur: una cacería de migrantes", en Animal Político (24 de abril de 2015). Artículo en línea disponible en: <https://pajaropolitico.com/caceria-de-migrantes/derechos-humanos-caza-miles-migrantes.php> [consultado el 10 de enero de 2018].

Rea, Daniela. "Juegan a ser sicarios", en Generación ;Bang! Nuevos cronistas del narco mexicano. Juan Pablo Meneses (comp.). México: Temas de Hoy, 2012. 177-180.

ReA, Daniela. Nadie les pidió perdón. Historias de impunidad y resistencia. México: Urano, 2015.

Ramos, Julıo. Desencuentros de la modernidad en América Latina. Literatura y política en el siglo XIX. México: Fondo de Cultura Económica, 1989.

RotKer, SusAna. La invención de la crónica. México: Fondo de Cultura Económica / Fundación para un Nuevo Periodismo Iberoamericano, 2005.

RoudinesCo, ÉlisABEtH. Nuestro lado oscuro. Una historia de los perversos [2007]. Barcelona: Anagrama, 2009.

SOFSKY, WOLFGANG. Tratado sobre la violencia [1996]. Madrid: Abada, 2006. 
Trías, Eugenio. Lo bello y lo siniestro [1982]. Barcelona: Ariel, 2009.

Turati, Marcela. "Muerte en el desierto", en vvaA. Lo mejor del periodismo de América Latina. México: Fondo de Cultura Económica / Fundación Nuevo Periodismo Iberoamericano, 2006. 521-539.

Turati, Marcela. "Guerra contra el luto", en Generación ;Bang! Nuevos cronistas del narco mexicano. Juan Pablo Meneses (comp.). México: Temas de Hoy, 2012. 227-235.

Turati, Marcela. "Santiago Meza López, 'El Pozolero'. Cuerpos sin sepultura", en Los malos. Leila Guerriero (ed.). Santiago de Chile: Ediciones Universidad Diego Portales, 2015. 93-135.

VAldeZ, JaVIer. Malayerba. La vida bajo el narco. México: Jus, 2016.

Valdez, Javier. Periodismo escrito con sangre. César Ramos (sel., pról. y notas). México: Aguilar, 2017.

Valencia, Sayak. Capitalismo Gore. Santa Cruz de Tenerife: Melusina, 2010.

Warren, Carl. Géneros periodísticos informativos. Alfonso Espinet (trad.). Barcelona: Harper and Row Publishers, 1975.

Wodak, Ruth y Michael Meyer (comps.). Métodos de análisis crítico del discurso. Barcelona: Gedisa, 2003.

Wolfe, Tom. El nuevo periodismo [1973]. José Luis Guarner (trad.). Barcelona: Anagrama, 1977.

Zimbardo, Phillip. El efecto Lucifer. El porqué de la maldad. Barcelona: Paidós, 2008.

Patricia Poblete Alday

Es periodista por la Universidad de Chile; doctora en Literatura Hispanoamericana por la Universidad Complutense de Madrid; profesora titular en la Universidad Academia de Humanismo Cristiano de Santiago de Chile — donde también dirige el departamento de publicaciones académicas-; e investigadora del sistema ConicytChile. Ha sido profesora visitante en las universidades Complutense de Madrid y de Guanajuato. Es autora de la novela Marcha atrás (2005), Premio Revista de Libros El Mercurio, y de los ensayos Bolaño, otra vuelta de tuerca (2010) y El mal como voluntad de la mirada: los cuentos de Francisco Tario (2011). Entre sus últimas publicaciones se encuentran: "Monstruos posmodernos. Figuras de la inmigración en el México contemporáneo", en Chasqui. Revista de Literatura Latinoamericana; "Espacios del mal 
y clichés en la crónica de inmigración norte y centroamericana actual" en Literatura y Lingüística; "Periodistas/ literatos: autoría, mercado y campo cultural", en Antonio López Hidalgo (coord.) Periodismo narrativo en América Latina. Quito; e "Hibridez y tradición en la crónica latinoamericana contemporánea. Los textos de Rafael Gumucio", en Revista Iberoamericana. 